Research Article

\title{
Diurnal Variation of Soil Heat Flux at an Antarctic Local Area during Warmer Months
}

\author{
Marco Alves and Jacyra Soares \\ Department of Atmospheric Science, IAG, University of São Paulo, 05508-090 São Paulo, SP, Brazil \\ Correspondence should be addressed to Jacyra Soares; jacyra@usp.br
}

Received 18 March 2016; Revised 15 April 2016; Accepted 28 April 2016

Academic Editor: Marco Trevisan

Copyright ( $) 2016$ M. Alves and J. Soares. This is an open access article distributed under the Creative Commons Attribution License, which permits unrestricted use, distribution, and reproduction in any medium, provided the original work is properly cited.

\begin{abstract}
Soil heat flux $(G)$ is one term in the energy balance equation, and it can be particularly important in regions with arid, bare, or thinly vegetated soil surfaces. However, in remote areas such as the Antarctic, this measurement is not routinely performed. The analysis of observational data collected by the ETA Project at the Brazilian Antarctic Station from December 2013 to March 2014 showed that, for the total daily energy flux, the surface soil flux heats the deeper soil layers during December and January and $G$ acts as a heat source to the outer soil layers during February and March. With regard to daytime energy flux, $G$ acts as a source of heat to the deeper layers. During the night-time, the soil is a heat source to the shallower soil layers and represents at least $29 \%$ of the net night-time radiation. A relatively simple method-the objective hysteresis method (OHM) - was successfully applied to determine the surface soil heat flux using net radiation observations. A priori, the OHM coefficients obtained in this study may only be used for short-time parameterizations and for filling data gaps at this specific site.
\end{abstract}

\section{Introduction}

Energy from the Sun plays an important role in climatic systems as a whole and a specific role in the Earth's radiation balance. Net radiation and soil heat flux provide the energy for sensible and latent atmospheric turbulent heat fluxes near the surface.

Surface soil heat flux $(G)$, defined as the heat exchange between different soil depths, with each layer possessing different temperature values [1], is a particularly important component of surface energy in regions with arid, bare, or thinly vegetated soil surfaces due to its capacity to work seasonally as a heat source (winter season) or a heat sink (summer season) [2-4]. Therefore, accuracy in the estimation of $G$ is important to atmospheric systems [5]. However, such estimates are not readily available, particularly in locations such as the Antarctic, which possesses extreme climatic conditions for measurements in situ and heterogeneity in surface properties.

Bare soils generally have low albedo, whereas ice-covered soils show high albedo $[6,7]$. Consequently, these soil types will have different soil temperatures even when in proximity to one another. For this reason, changes in Antarctic soil coverage can lead to local variation in temperature, directly affecting the Antarctic ecosystem [8].

Previous research has also suggested that soil temperature changes can have a marked impact on affecting the biological processes [9-15].

Prosek et al. [16] investigating the components of energy balance in a vegetated oasis at the Polish Station (King George Island, Antarctic region) have found that the boundary atmosphere and the soil substrate represent the basic components of the ecotopes of the Antarctic vegetation oasis.

Sturm et al. [17] discussed the warming in Alaska, of $0.5^{\circ} \mathrm{C}$ per decade in the last 30 years, and the positive feedback involving biological processes in the winter soil, which have contributed to the conversion of tundra to shrubland.

The direct estimation of soil heat flux by remotely sensed data is not feasible [18]. However, empirical relationships between $G$ and the net radiation $\left(R_{n}\right)$ can be used to determine $G$ [19]. 


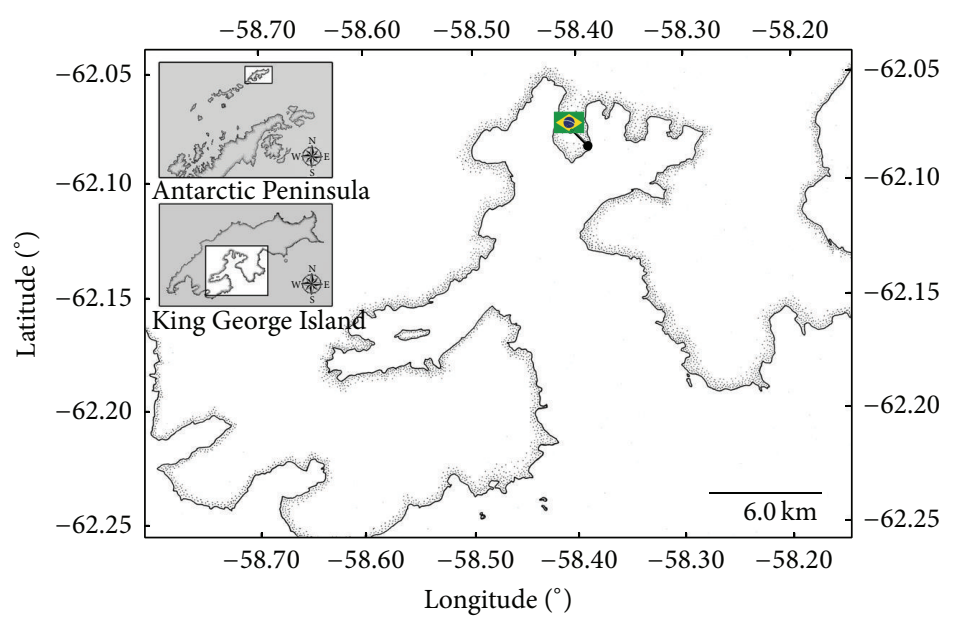

FIgURE 1: Geographical location of the EACF. Adapted from [32].

The objective hysteresis method (OHM) was proposed by Camuffo and Bernardi [20] to estimate $G$ using values of $R_{n}$. The OHM model was initially developed for urban areas in an attempt to estimate urban heat storage as a residual term with different sources/sinks of energy such as buildings, vegetation, and the ground responsible for the exchange of sensible and latent heat fluxes [21-23]. However, there is nothing in the formulation of the OHM that limits its application only to urban areas.

This study uses a method of hysteresis to estimate soil heat flux and compare these estimates to direct measurements performed at the Brazilian Antarctic Station "Comandante Ferraz" (EACF) from December 2013 to March 2014. The data used in this study was collected by the ETA Project (Estudo da Turbulência na Região Antártica). To our knowledge, this is the first application of this method to the EACF region. Most of the previously published values are for urban areas and they are not valid for the studied region and time period.

\section{Materials and Methods}

The measurements were performed at the EACF $\left(62^{\circ} 05^{\prime} 07^{\prime \prime} \mathrm{S}\right.$, $58^{\circ} 23^{\prime} 33^{\prime \prime} \mathrm{W}, 20 \mathrm{~m}$ above mean sea level) at a micrometeorological tower, located on King George Island, which is part of the South Shetland Islands of the Antarctic Peninsula (Figure 1).

The micrometeorological tower is surrounded by surface of different characteristics. Figure 2 presents an overview of the investigated area and shows the soil cover commonly observed, varying from bare soil to snow-covered soil.

During warmer months, the surface is covered mostly by bare soil, with presence of diverse sizes of rocks and gravels $(<1 \mathrm{~m}$ in width). The occurrence of snow due to atmospheric systems, in these months, is unavailable. Nearby the tower there is a lake $(<10 \mathrm{~m})$, commonly frozen during the year, except on some days of summer.
The data used in this study were collected in situ from December 2013 to March 2014 (the warmer months). The net radiation data were obtained using a NR Lite2 Net Radiometer installed in a micrometeorological tower $(3.4 \mathrm{~m}$ in height, Figures 3(a) and 3(c)) and the surface soil heat flux was measured using a Hukseflux HFP01 at a depth of $0.05 \mathrm{~m}$ (Figure 3(b)). The air temperature was measured by temperature sensor Model CS215, mounted with a 6-plate radiation shield, installed at $2.2 \mathrm{~m}$ height. The plate louvered construction allows air to pass freely through the shield, serving to keep the probe at or near ambient temperature. The shield's white colour reflects solar radiation. The soil temperature was measured using a probe $107 \mathrm{~L}$ at $0.05 \mathrm{~m}$ depth. All sensors used in this work are from Campbell Scientific Inc.

The data were stored at $5 \mathrm{~min}$ (average) intervals by a CR5000 data logger (Campbell Scientific Inc.) using the local time (LT $=-04$ UTC) as the standard time (Figure 3). The data logger was connected to a laptop that automatically transmitted the data, every $30 \mathrm{~min}$, to the Air-Sea Interaction Laboratory at IAG, USP. All data were reviewed and questionable data were removed considering the values located out of the 2-standard-deviation interval centred on the average value of the investigated variable.

The sign convention used for this study is that $R_{n}$ and $G$ are positive when energy is moving up in agreement with the vertical coordinate $z$.

\subsection{The Objective Hysteresis Method and Statistical Evaluation} of the OHM Application. The estimation of $G$ using the objective hysteresis method (OHM) was based on the expression given by [20]

$$
G=a_{1} R_{n}+a_{1} \frac{\partial R_{n}}{\partial t}+a_{3},
$$

where $a_{1}, a_{2}$, and $a_{3}$ are empirical coefficients related to the response of the surface properties due to solar energy 


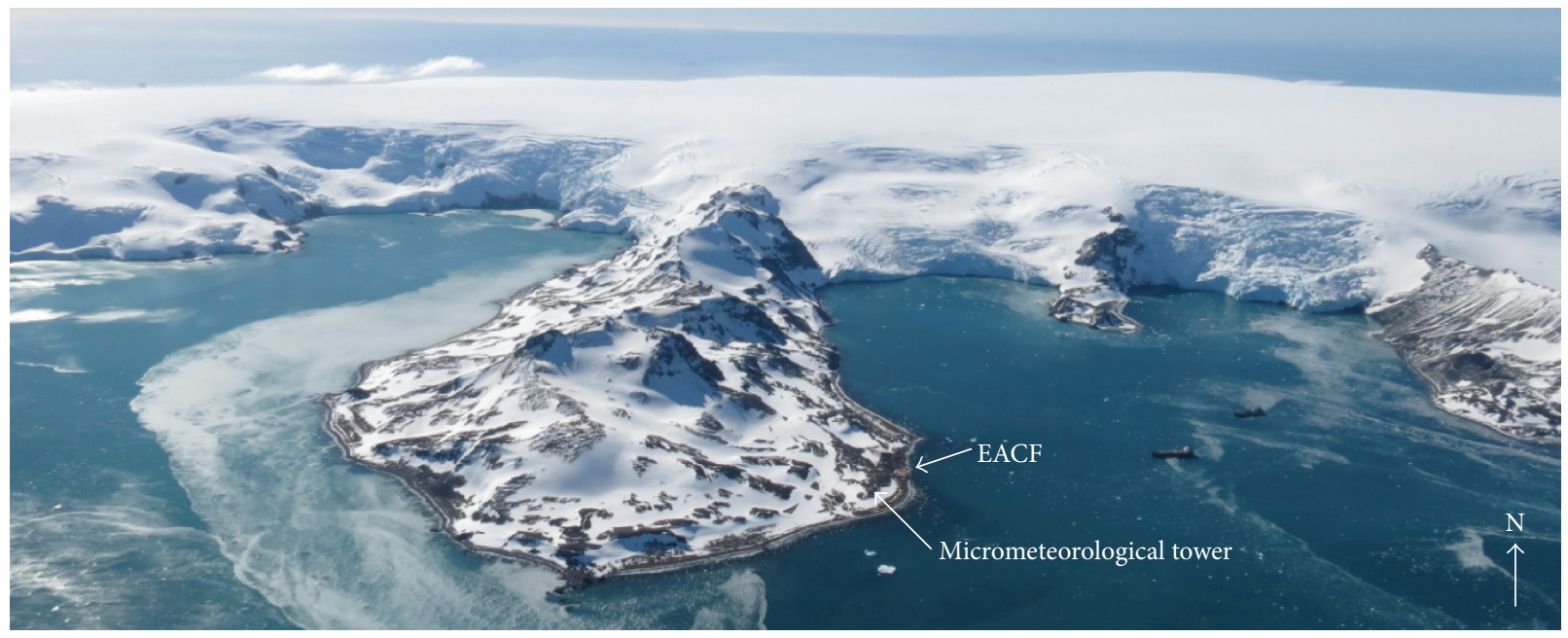

(a)

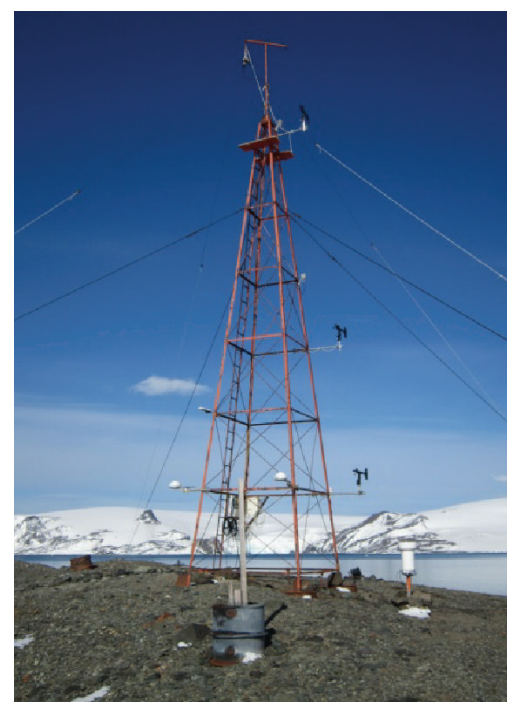

(b)

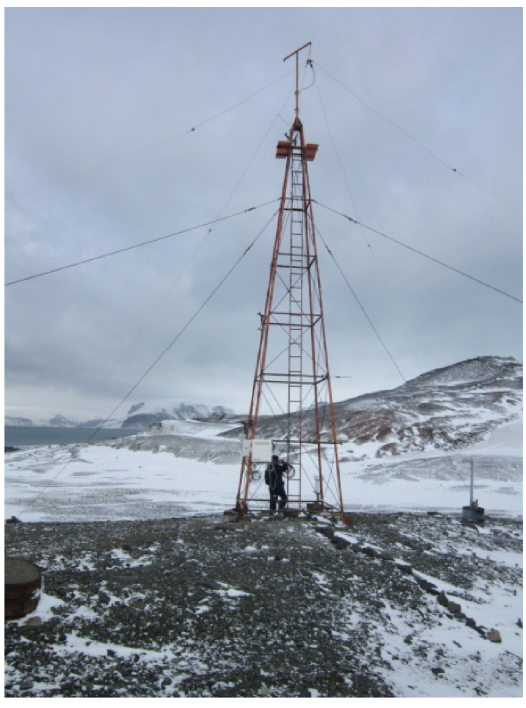

(c)

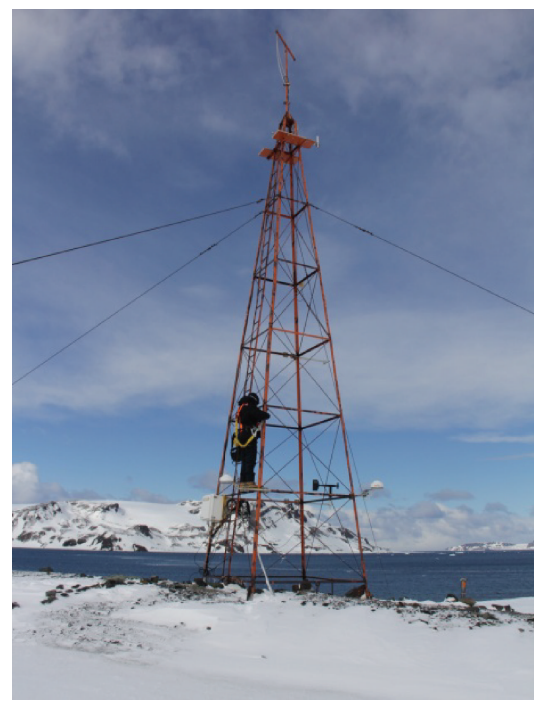

(d)

FIGURE 2: (a) Overview of the investigated area (photography copyright Renato Torlay). Micrometeorological tower region surrounded by (b) bare soil, (c) bare and snow-covered soil, and (d) snow-covered soil.

and $\partial R_{n} / \partial t$ is the temporal variation of $R_{n}$ at the surface, discretized in time as $\partial R_{n} / \partial t=0.5\left(R_{n}^{t+1}-R_{n}^{t-1}\right)$. The $a_{1}$ and $a_{3}$ coefficients describe the best-fit straight line for the data over the entire day and are therefore constants. The slope of the best-fit straight line is represented by $a_{1}$ and the intercept with the ordinate is represented by $a_{3}$. The $a_{2}$ coefficient indicates the departure of actual values from the best-fit straight line.

The coefficients play different roles in the equation: $a_{1}$ is dimensionless and always positive and indicates the intensity of the relation between $R_{n}$ and $G ; a_{2}$ (s) shows the magnitude of the hysteresis, indicating the direction and the degree of the phase relationship between $R_{n}$ and $G$. In summary, $a_{1}$ and $a_{2}$ are coefficients related to the mean values resulting from the soil characteristics (including the presence of water) and to the magnitude of $R_{n}$ with its temporal variation [20].

The coefficient $a_{3}\left(\mathrm{Wm}^{-2}\right)$ may be negative or positive depending on the local atmospheric conditions, and it represents the spontaneous heat flux between the soil and the adjacent atmosphere, when $R_{n}$ and $\partial R_{n} / \partial t$ approach zero. In other words, this term represents the average heat flux released from the soil during the transitional periods of the day $[20,22,24]$.

Statistical tests were performed to evaluate the application of the OHM model to the EACF region, including a linear regression with slope and intercept, coefficient of determination $\left(R^{2}\right)$, root mean square error (RMSE), and the mean absolute error (MAE). 


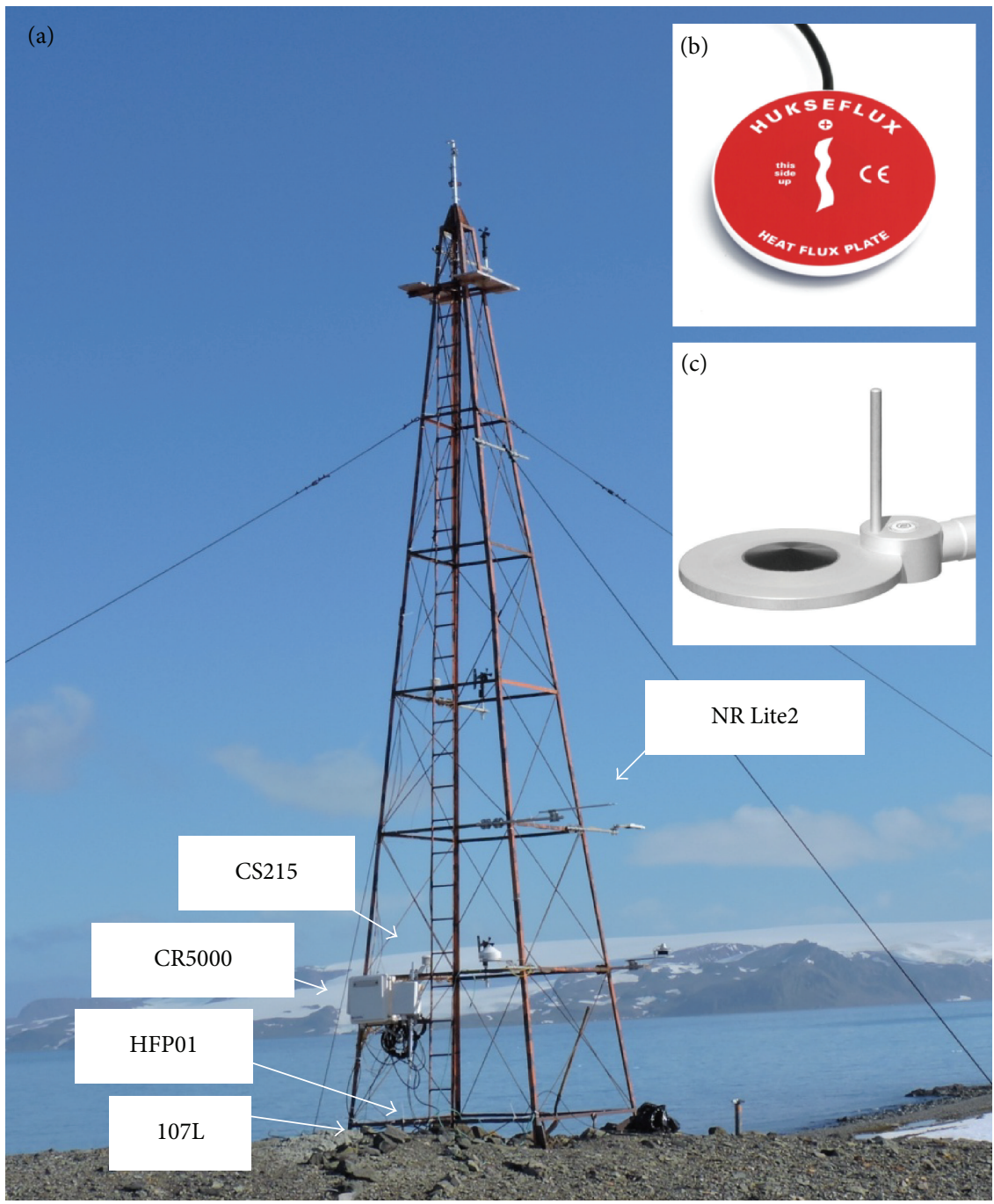

FIgURE 3: (a) Micrometeorological tower at the EACF, (b) soil heat flux instrument (HFP01), and (c) net radiation instrument (NR Lite2).

$R^{2}$ represents the percentage of the data that is close to the line of the best fit; these variances can be understood by the regression model [25]. The coefficient is given by

$$
\begin{aligned}
& R^{2} \\
& {\left[\sum_{i=1}^{N}\left(G_{i, \mathrm{obs}}-\overline{G_{\mathrm{obs}}}\right)^{2}\right]^{0.5}\left[\sum_{i=1}^{N}\left(G_{i, \mathrm{mod}}-\overline{G_{\mathrm{mod}}}\right)^{2}\right]^{0.5}}
\end{aligned}
$$

where $N$ is the total number of observations, $G_{i, \text { obs }}$ is the " $i$ " observation value, and $G_{i, \bmod }$ is the " $i$ " modelled result. The overbar denotes the time average for the period of evaluation. $R^{2}$ ranges from 0 to 1 , with values near 1 indicating a good fit of the modelled results.
The performance of a model can also be quantified using an error value with the same units as the variable. The RMSE and MAE represent such quantifications [25-27]:

$$
\begin{aligned}
\text { RMSE } & =\sqrt{\frac{1}{N} \sum_{i=1}^{N}\left(G_{i, \mathrm{obs}}-G_{i, \mathrm{mod}}\right)^{2}}, \\
\mathrm{MAE} & =\frac{1}{N} \sum_{i=1}^{N}\left|G_{i, \mathrm{obs}}-G_{i, \bmod }\right| .
\end{aligned}
$$

In general, the RMSE is greater than or equal to the MAE for the range of most values because the MAE is less sensitive to extreme values than the RMSE. 


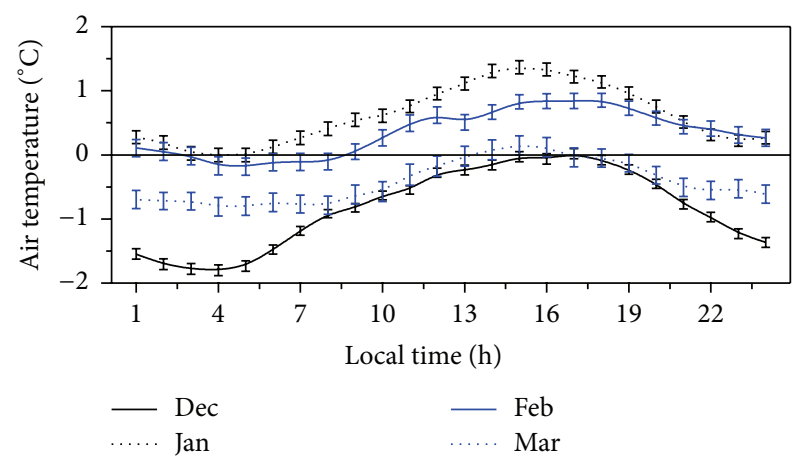

(a)

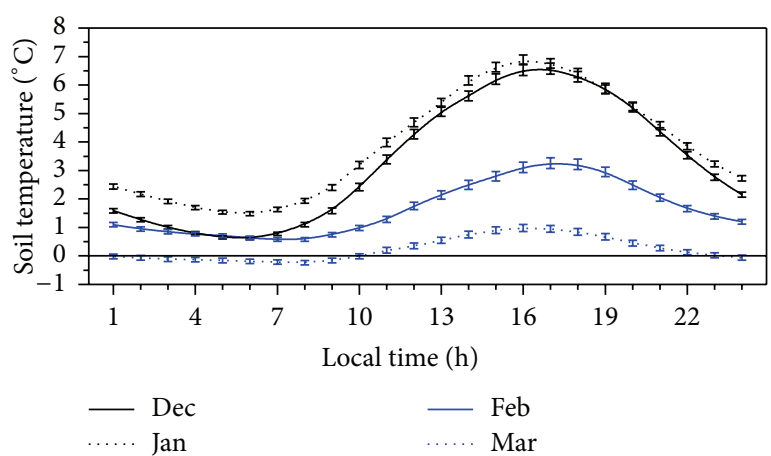

(b)

FIGURE 4: Diurnal variation of hourly average of (a) air temperature and (b) soil temperature for December 2013 to March 2014 . The vertical bars indicate the standard error.

TABLE 1: Summary of daily energy fluxes $\left(R_{n}\right.$ and $\left.G\right)$, partitioned into daytime, night-time, and daily fluxes.

\begin{tabular}{|c|c|c|c|c|c|c|c|c|c|c|}
\hline \multirow[b]{2}{*}{ Month } & \multirow[b]{2}{*}{ Average daylight time (h) } & \multicolumn{3}{|c|}{ Daytime energy flux } & \multicolumn{3}{|c|}{ Night-time energy flux } & \multicolumn{3}{|c|}{ Daily total energy flux } \\
\hline & & $\begin{array}{l}R_{n} \\
(\mathrm{MJ} \mathrm{m}\end{array}$ & $\begin{array}{c}G \\
\left.2 \mathrm{~d}^{-1}\right) \\
\end{array}$ & $\begin{array}{c}G / R_{n} \\
(\%)\end{array}$ & $\begin{array}{l}R_{n} \\
(\mathrm{MJ})\end{array}$ & $\begin{array}{c}G \\
\left.2 \mathrm{~d}^{-1}\right) \\
\end{array}$ & $\begin{array}{c}G / R_{n} \\
(\%)\end{array}$ & $\begin{array}{l}R_{n} \\
(\mathrm{MJ} \mathrm{r}\end{array}$ & $\begin{array}{c}G \\
\left.2 \mathrm{~d}^{-1}\right)\end{array}$ & $\begin{array}{c}G / R_{n} \\
(\%)\end{array}$ \\
\hline December 2013 & 19.1 & -8.72 & -0.66 & 7.6 & 0.54 & 0.31 & 57.4 & -8.18 & -0.35 & 4.3 \\
\hline January 2014 & 18.1 & -8.39 & -0.40 & 4.8 & 0.72 & 0.36 & 50.0 & -7.67 & -0.04 & 0.5 \\
\hline February 2014 & 15.4 & -4.09 & -0.17 & 4.2 & 0.54 & 0.20 & 37.0 & -3.55 & 0.04 & -1.1 \\
\hline March 2014 & 12.5 & -2.19 & -0.03 & 1.4 & 0.88 & 0.26 & 29.5 & -1.31 & 0.23 & -17.6 \\
\hline
\end{tabular}

\section{Results and Discussion}

The soil temperature, during the investigated period, was always higher than the air temperature, as observed in cold regions [28]. January presented higher air and soil temperatures with a diurnal amplitude around, respectively, $1.4^{\circ} \mathrm{C}$ and $5.4^{\circ} \mathrm{C}$ (Figure 4). Among the investigated months, the diurnal variation of the soil temperature presented larger amplitudes than the air temperature, with maximum amplitude in December in both cases. Unfortunately, there is no data available during the investigated months directly related to the snow presence (surface albedo and emissivity, latent heat, etc.) but, in general, large soil temperature amplitude is characteristic of bare soil. During February and March most of the air temperature values were below zero and the diurnal amplitudes of the soil temperatures are comparatively smaller which could indicate the snow presence during these months. Previous studies have indicated that a characteristic of snow cover would be a long period of relatively stable soil temperatures with smaller amplitude of the temperature signal [13, 29].

December and January have more hours of daylight (Table 1) and consequently larger amount of net radiation compared to the other investigated months (Figure 5).

Through all investigated months there was a delay between $G$ and $R_{n}$ during the two periods of the day corresponding to the transitional day/night/day periods when the signal of $R_{n}$ and $G$ are inverted, with the soil acting as a source
TABLE 2: Monthly coefficients of the OHM applied to the EACF region.

\begin{tabular}{lccc}
\hline Month & \multicolumn{3}{c}{ Coefficient } \\
& $a_{1}$ & $a_{2}(\mathrm{~s})$ & $a_{3}\left(\mathrm{~W} \mathrm{~m}^{-2}\right)$ \\
\hline December 2013 & 0.17 & -0.09 & 11.8 \\
January 2014 & 0.13 & -0.03 & 11.5 \\
February 2014 & 0.11 & -0.10 & 5.6 \\
March 2014 & 0.10 & -0.068 & 4.3 \\
\hline
\end{tabular}

of heat to the shallower soil layers and $R_{n}$ as a source of heat to the soil (Figure 5).

In general, during the daytime, the energy provided by $R_{n}$ is shared between $G$ and the turbulent fluxes, but during the night-time, the turbulent fluxes are less important and $G$ represents a comparatively larger portion of the net radiation. Therefore, at night, the soil played an important role as an energy source to the outer soil layers accounting for approximately $31 \%$ of $R_{n}$ in March and up to approximately $55 \%$ of $R_{n}$ in December (Table 1, Figure 6). High values of $G / R_{n}$ occurred near the transitional periods, when $R_{n}$ was low but, near noon, $G$ was approximately $10 \%$ of $R_{n}$ (Figure 6 ) as observed by several authors in different locations [30,31].

During the daytime of the studied period, part of the net energy was stored in the soil, with maximum storage of approximately 7.6\% observed in December (Table 1). During January, the quantity of net radiation energy flux incident 


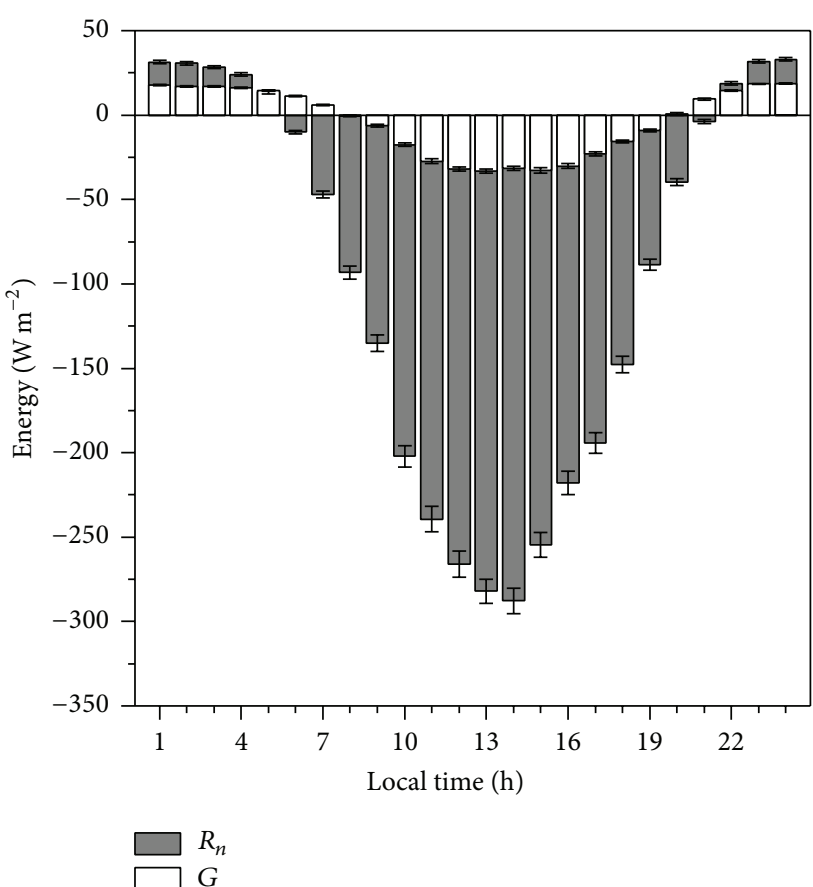

(a)

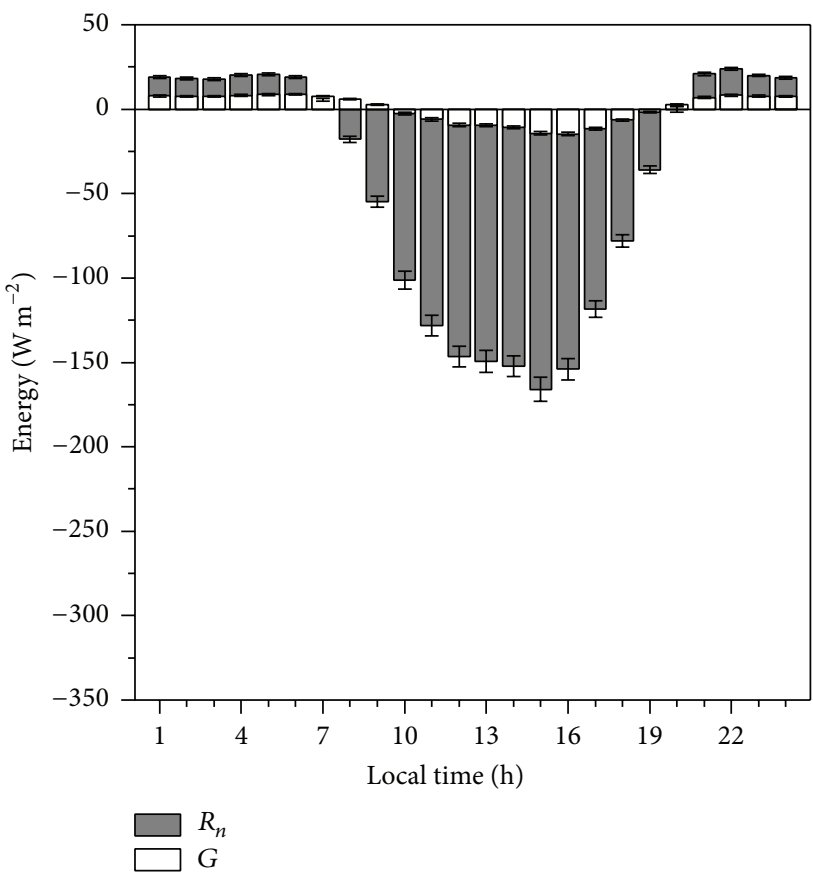

(c)

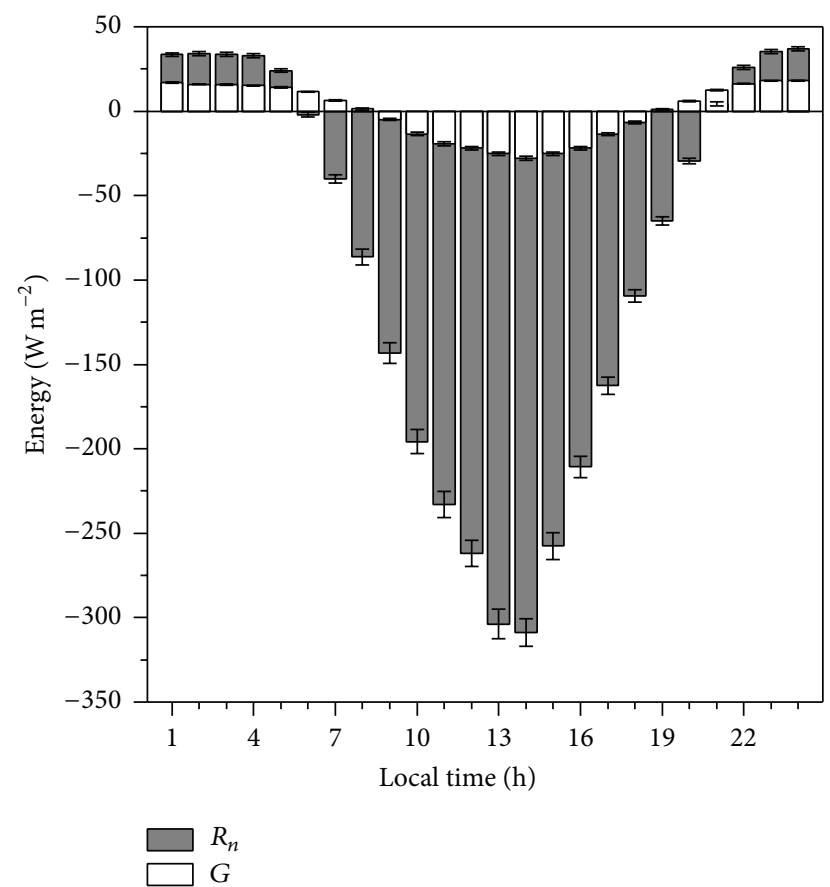

(b)

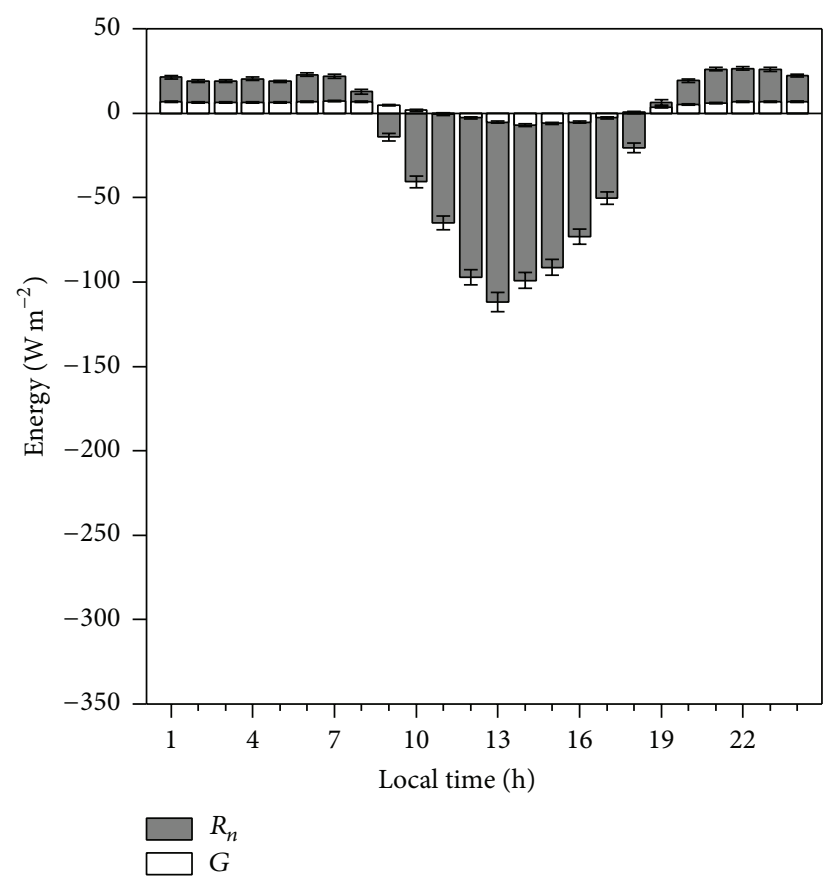

(d)

FIGURE 5: Diurnal variation of hourly average net radiation $\left(R_{n}\right)$ and soil heat flux $(G)$ for (a) Dec 2013, (b) Jan 2014, (c) Feb 2014, and (d) Mar 2014. The vertical bars indicate the standard error.

on the surface was more than twice the quantity of incident energy during February, but the proportion of energy stored in the soil was not so different.

In the EACF region, the daily ratio of $G / R_{n}$ varied from $4.3 \%$ in December to $-17.6 \%$ in March (Table 1) with the soil acting as a heat source to the deeper soil layers during
December and January (positive values of $G / R_{n}$ ) and as a source of heat to the shallower soil layers (negative values of $G / R_{n}$ ) during February and March (Table 1).

The best-fit coefficients for the investigated months are shown in Table 2 and, a priori, these values are valid for this particular site during this period of study because 
TABLE 3: Statistical evaluation of observed and modelled soil heat flux for the investigated months.

\begin{tabular}{|c|c|c|c|c|c|}
\hline Month & Slope & Intercept $\left(\mathrm{W} \mathrm{m}^{-2}\right)$ & $R^{2}$ & $\operatorname{RMSE}\left(\mathrm{W} \mathrm{m}^{-2}\right)$ & $\operatorname{MAE}\left(\mathrm{W} \mathrm{m}^{-2}\right)$ \\
\hline December 2013 & 0.97 & 0.29 & 0.992 & 1.85 & 1.32 \\
\hline January 2014 & 1.03 & -0.33 & 0.991 & 1.64 & 1.33 \\
\hline February 2014 & 1.01 & -0.10 & 0.994 & 0.64 & 0.50 \\
\hline March 2014 & 0.99 & 0.03 & 0.990 & 0.51 & 0.35 \\
\hline
\end{tabular}

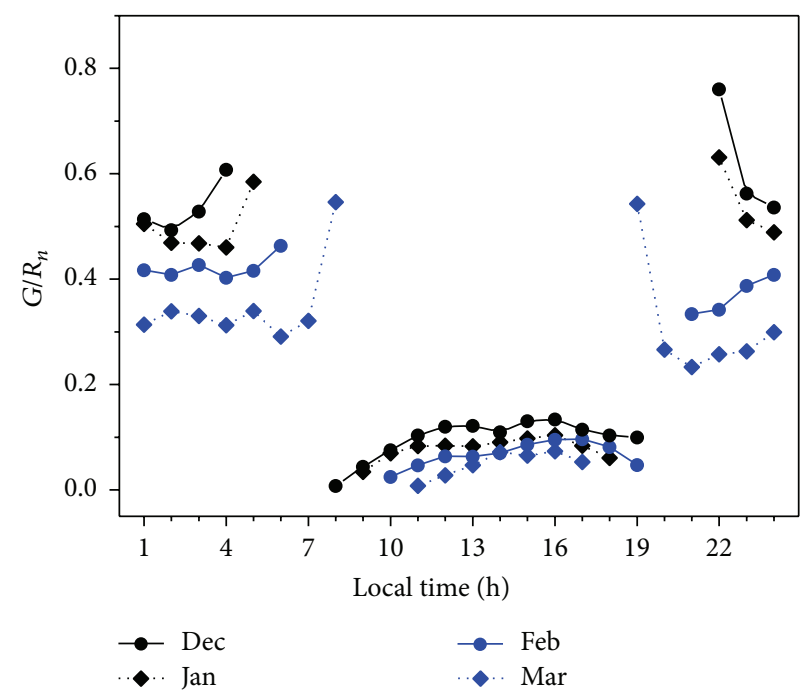

FiguRE 6: Diurnal variation of hourly average fraction of soil heat flux $(G)$ as a percentage of net radiation $\left(R_{n}\right)$ for December 2013 to March 2014. Data for the transitional periods were removed from the figure.

these coefficients are related to the presence of precipitation, atmospheric system, soil state, and soil characteristics. Using these coefficients (Table 2), the OHM was able to simulate the diurnal variation of $G$ during the investigated months, as displayed in Figure 7.

Statistical tests were performed to evaluate the OHM application to the investigated region and all months showed a high degree of statistical agreement between observed and modelled values with slopes near 1, intercept values of approximately zero, and $R^{2}$ values greater than 0.99 . In addition, the RMSE and MAE values were less than $1.85 \mathrm{Wm}^{-2}$ and $1.33 \mathrm{Wm}^{-2}$, respectively (Table 3 ).

From the hysteresis graph of diurnal variation in the observed and modelled values of $G$ against the $R_{n}$ values, it can be seen that the eccentricities of the ellipses from December 2013 and January 2014 were larger than those from February and March 2014 (Figure 7) and during the transitional period, $G$ and $R_{n}$ showed opposite signals (I in Figure 7), with the soil releasing more heat to the shallower layers at the beginning of the day than at the end of the day (Figures 5 and 7 ).

\section{Conclusions}

Despite its importance, measurement of soil heat flux is not performed routinely, particularly in remote areas such as the region investigated here. This study applied an indirect method (OHM) proposed by [20] to estimate soil heat flux using values of observed net radiation.

This study used 5-minute averages of surface soil heat flux and net radiation observed at the Brazilian Station Comandante Ferraz from December 2013 to March 2014. The observed daily total energy flux indicated that, during December and January, $G$ was a source of heat to the soil deeper layers and $R_{n}$ was a heat source to the soil. However, during February and March, $G$ and $R_{n}$ have inverse directions with $G$ releasing heat to the outer soil layers. During the daytime of the investigated months, $G$ and $R_{n}$ heated the soil. During the night-time, $G$ represents at least $29 \%$ of $R_{n}$. Therefore, $G$ cannot be ignored in the energy balance equation of the EACF region.

The OHM was able to estimate the surface soil heat flux for each studied month, with all correlation coefficients exceeding 99\%.

Future analyses will involve the application of the OHM to all months of the year and investigate the validity of the expressions obtained here for the same months of different years. It is important to note that the coefficients obtained in this study can only be used for short-time parameterizations at a specific site and for filling data gaps.

\section{Competing Interests}

The authors declare that there are no competing interests regarding the publication of this paper. 


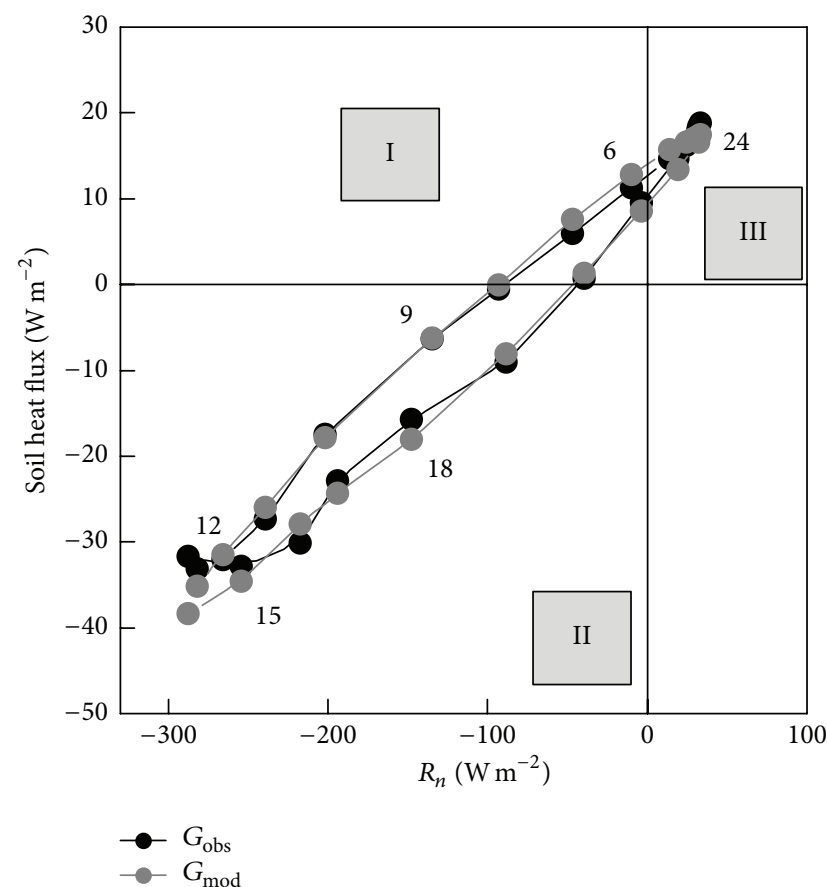

(a)

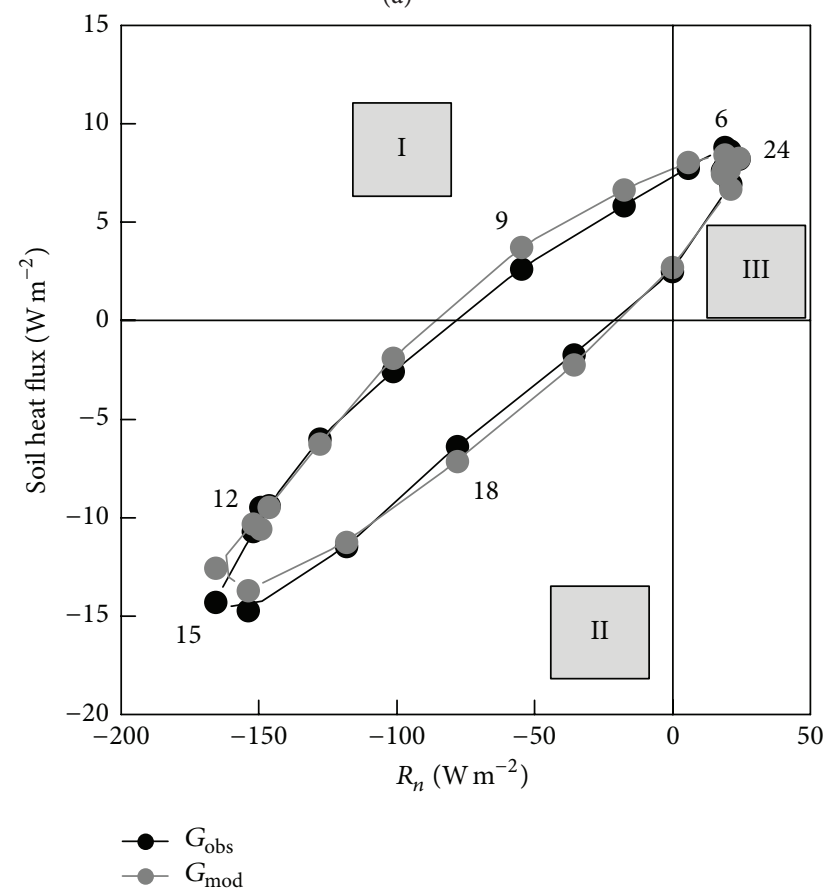

(c)

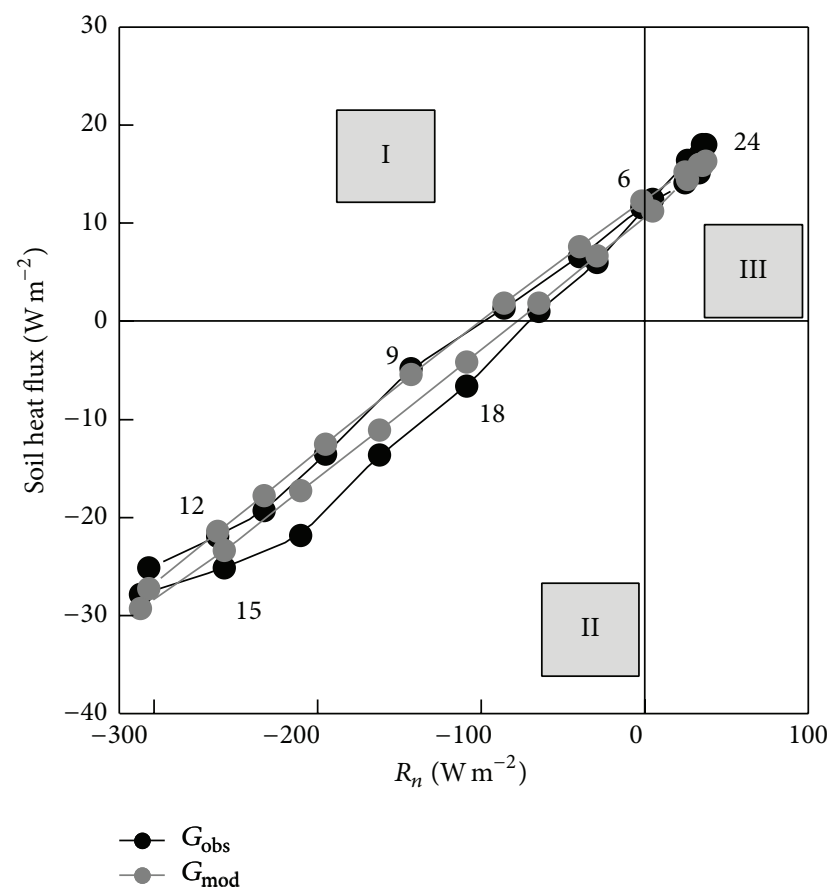

(b)

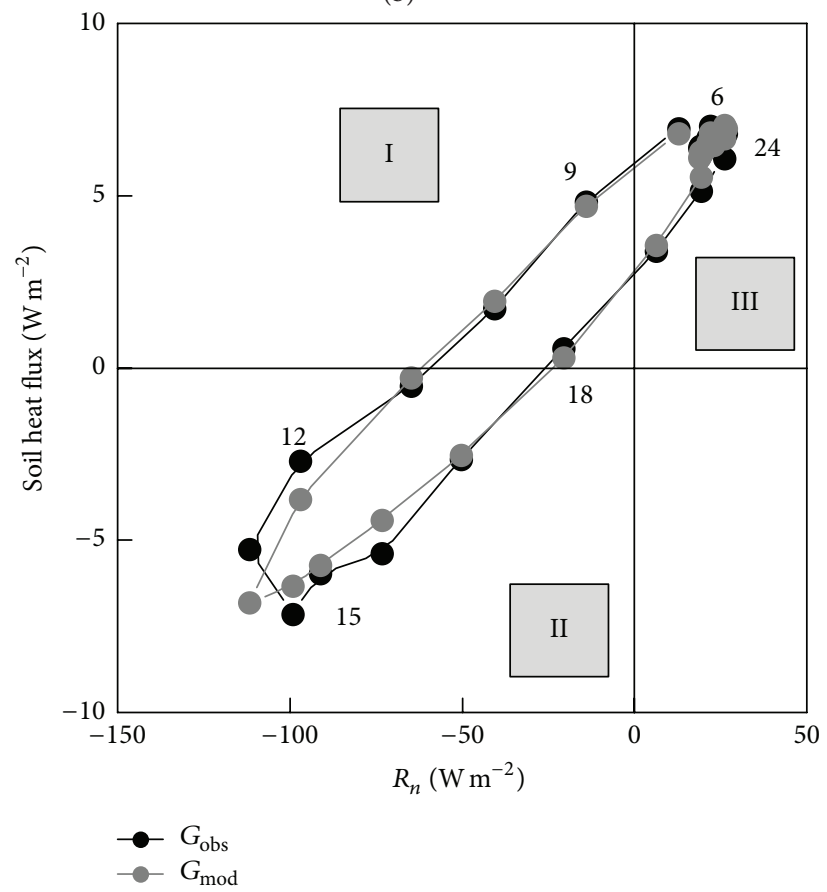

(d)

FiguRE 7: Hysteresis loop relations between observed (obs, black colour) and modelled (mod, grey colour) soil heat flux $(G)$ and net radiation $\left(R_{n}\right)$ in the EACF: (a) December 2013, (b) January 2014, (c) February 2014, and (d) March 2014. The numbers represent the local time (hour). I, II, and III indicate the period of the day: transitional, daytime, and night-time periods, respectively.

\section{Acknowledgments}

The first author acknowledges a scholarship from CAPES. All authors would like to thank the grants of "INCT-APA" (CNPq 574018/2008-5 and FAPERJ E-16/170.023/2008). The second author also thanks CNPq (305357/2012-3 and 407137/2013-0).

\section{References}

[1] C. M. Bhumralkar, "Numerical experiments on the computation of ground surface temperature in an atmospheric general circulation model," Journal of Applied Meteorology, vol. 14, no. 7, pp. 1246-1258, 1975. 
[2] K. Anandakumar, R. Venkatesan, and T. V. Prabha, "Soil thermal properties at Kalpakkam in Coastal South India," Proceedings of the Indian Academy of Sciences, Earth and Planetary Sciences, vol. 110, no. 3, pp. 239-245, 2001.

[3] T. Choi, B. Y. Lee, S.-J. Kim, Y. J. Yoon, and H.-C. Lee, "Net radiation and turbulent energy exchanges over a non-glaciated coastal area on King George Island during four summer seasons," Antarctic Science, vol. 20, no. 1, pp. 99-112, 2008.

[4] S. E. Sofyan, E. Hu, and A. Kotousov, "A new approach to modelling of a horizontal geo-heat exchanger with an internal source term," Applied Energy, vol. 164, pp. 963-971, 2016.

[5] P. Viterbo, A. Beljaars, J.-F. Mahfouf, and J. Teixeira, "The representation of soil moisture freezing and its impact on the stable boundary layer," Quarterly Journal of the Royal Meteorological Society, vol. 125, no. 559, pp. 2401-2426, 1999.

[6] R. J. L. MacCulloch, The microclimatology of Antarctic soils [Master of Sciences in Earth Sciences], University of Waikato, Hamilton, New Zealand, 1996.

[7] D. I. Campbell, R. J. MacCulloch, and I. B. Campbell, “Thermal regimes of some soils in the McMurdo Sound region, Antarctica," in Ecosystem Processes in Antarctic Ice-Free Landscapes: Proceedings of an International Workshop on Polar Desert Ecosystems Christchurch, New Zealand 1-4 July, 1996, W. B. Lyons, C. Howard-Williams, and I. Hawes, Eds., A.A. Balkema, Rotterdam, The Netherlands, 1997.

[8] A. J. Oliphant, R. C. A. Hindmarsh, N. J. Cullen, and W. Lawson, "Microclimate and mass fluxes of debris-laden ice surfaces in Taylor Valley, Antarctica," Antarctic Science, vol. 27, no. 1, pp. 85-100, 2015.

[9] F. S. Chapin III, "Direct and indirect effects of temperature on arctic plants," Polar Biology, vol. 2, no. 1, pp. 47-52, 1983.

[10] M. C. Davey, J. Pickup, and W. Block, “Temperature variation and its biological significance in fellfield habitats on a maritime Antarctic island," Antarctic Science, vol. 4, no. 4, pp. 383-388, 1992.

[11] L. S. Peck, P. Convey, and D. K. A. Barnes, "Environmental constraints on life histories in Antarctic ecosystems: tempos, timings and predictability," Biological Reviews of the Cambridge Philosophical Society, vol. 81, no. 1, pp. 75-109, 2006.

[12] N. S. Haussmann, J. C. Boelhouwers, and M. A. Mcgeoch, "Fine scale variability in soil frost dynamics surrounding cushions of the dominant vascular plant species (Azorella selago) on subAntarctic Marion Island," Geografiska Annaler Series A: Physical Geography, vol. 91, no. 4, pp. 257-268, 2009.

[13] N. Cutler, "Vegetation-environment interactions in a sub-arctic primary succession," Polar Biology, vol. 34, no. 5, pp. 693-706, 2011.

[14] S. Bokhorst, A. H. L. Huiskes, R. Aerts et al., "Variable temperature effects of Open Top Chambers at polar and alpine sites explained by irradiance and snow depth," Global Change Biology, vol. 19, no. 1, pp. 64-74, 2013.

[15] W. Kellmann-Sopyła and I. Giełwanowska, "Germination capacity of five polar Caryophyllaceae and Poaceae species under different temperature conditions," Polar Biology, vol. 38, no. 10, pp. 1753-1765, 2015.

[16] P. Prosek, M. Janouch, and K. Láska, "Components of the energy balance of the ground surface and their effect on the thermics of the substrata of the vegetation oasis at Henryk Arctowski Station, King George Island, South Shetland Islands," Polar Record, vol. 36, no. 196, pp. 3-18, 2000.
[17] M. Sturm, J. Schimel, G. Michaelson et al., "Winter biological processes could help convert arctic tundra to shrubland," BioScience, vol. 55, no. 1, pp. 17-26, 2005.

[18] C. S. T. Daughtry, W. P. Kustas, M. S. Moran et al., "Spectral estimates of net radiation and soil heat flux," Remote Sensing of Environment, vol. 32, no. 2-3, pp. 111-124, 1990.

[19] C. Liebethal and T. Foken, "Evaluation of six parameterization approaches for the ground heat flux," Theoretical and Applied Climatology, vol. 88, no. 1-2, pp. 43-56, 2007.

[20] D. Camuffo and A. Bernardi, "An observational study of heat fluxes and their relationships with net radiation," BoundaryLayer Meteorology, vol. 23, no. 3, pp. 359-368, 1982.

[21] C. S. B. Grimmond, H. A. Cleugh, and T. R. Oke, "An objective urban heat storage model and its comparison with other schemes," Atmospheric Environment-Part B: Urban Atmosphere, vol. 25, no. 3, pp. 311-326, 1991.

[22] C. S. B. Grimmond and T. R. Oke, "Heat storage in urban areas: local-scale observations and evaluation of a simple model," Journal of Applied Meteorology, vol. 38, no. 7, pp. 922-940, 1999.

[23] S. K. Meyn and T. R. Oke, "Heat fluxes through roofs and their relevance to estimates of urban heat storage," Energy and Buildings, vol. 41, no. 7, pp. 745-752, 2009.

[24] M. J. Ferreira, A. P. De Oliveira, and J. Soares, "Diurnal variation in stored energy flux in São Paulo city, Brazil," Urban Climate, vol. 5, pp. 36-51, 2013.

[25] D. R. Legates and G. J. McCabe Jr., "Evaluating the use of 'goodness-of-fit' measures in hydrologic and hydroclimatic model validation," Water Resources Research, vol. 35, no. 1, pp. 233-241, 1999.

[26] C. J. Willmott, "Some comments on the evaluation of model performance," Bulletin of the American Meteorological Society, vol. 63, pp. 1309-1313, 1982.

[27] J. Soares, A. P. Oliveira, M. Z. Božnar, P. Mlakar, J. F. Escobedo, and A. J. Machado, "Modeling hourly diffuse solar-radiation in the city of São Paulo using a neural-network technique," Applied Energy, vol. 79, no. 2, pp. 201-214, 2004.

[28] T. Zhang, "Influence of the seasonal snow cover on the ground thermal regime: an overview," Reviews of Geophysics, vol. 43, no. 4, Article ID RG4002, 2005.

[29] G. Kudo, "Effects of snow-free period on the phenology of alpine plants inhabiting snow patches," Arctic \& Alpine Research, vol. 23, no. 4, pp. 436-443, 1991.

[30] B. E. Clothier, K. L. Clawson, P. J. Pinter Jr., M. S. Moran, R. J. Reginato, and R. D. Jackson, "Estimation of soil heat flux from net radiation during the growth of alfalfa," Agricultural and Forest Meteorology, vol. 37, no. 4, pp. 319-329, 1986.

[31] D. D. Baldocchi, S. B. Verma, and N. J. Rosenberg, "Water use efficiency in a soybean field: influence of plant water stress," Agricultural and Forest Meteorology, vol. 34, no. 1, pp. 53-65, 1985.

[32] R. B. Moura, Estudo taxonômico dos holothuroidea (echinodermata) das ilhas shetland do sul e do estreito de bransfield, antártica [M.S. thesis], Museu Nacional, Universidade Federal do Rio de Janeiro, Rio de Janeiro, Brazil, 2009. 

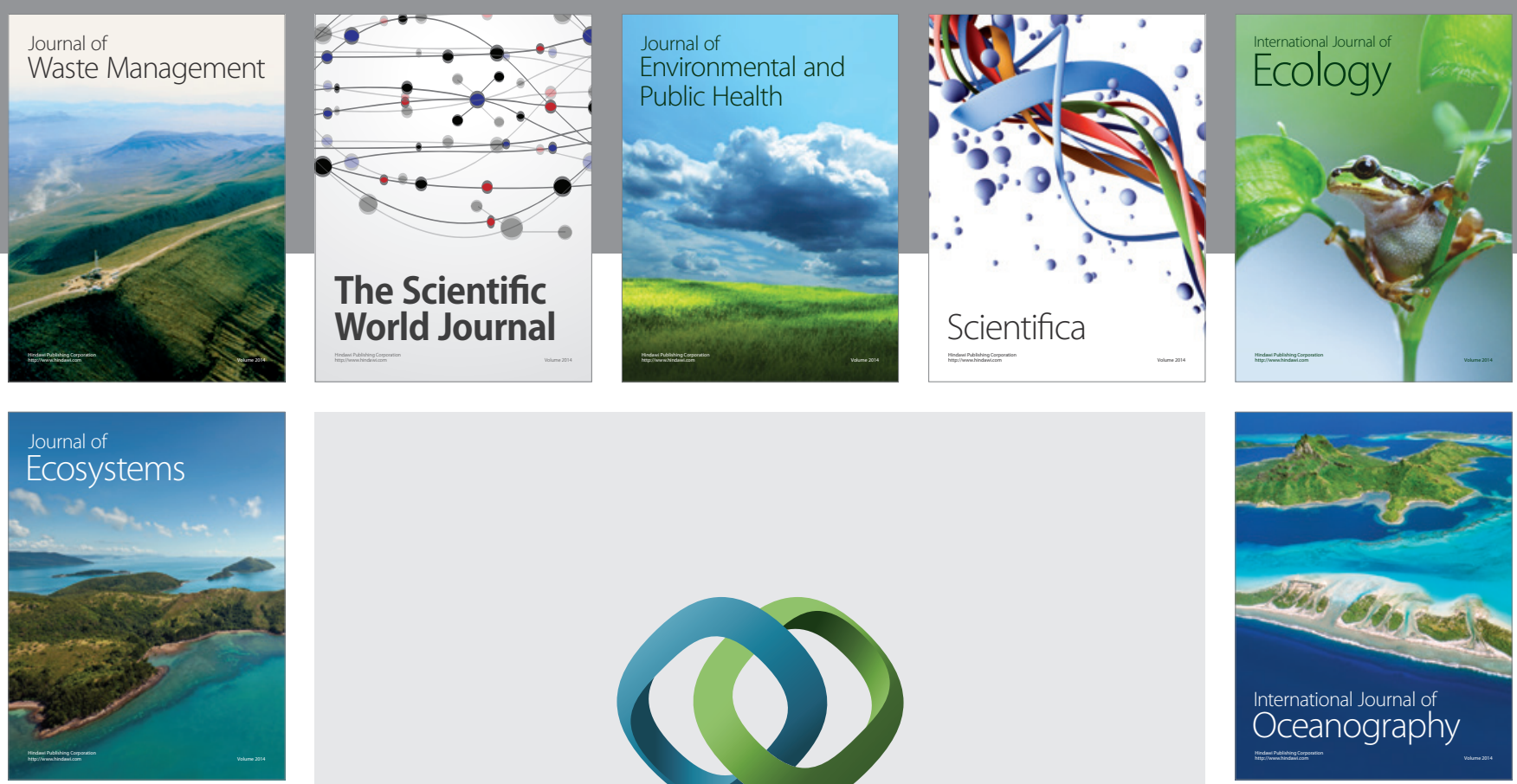

The Scientific World Journal
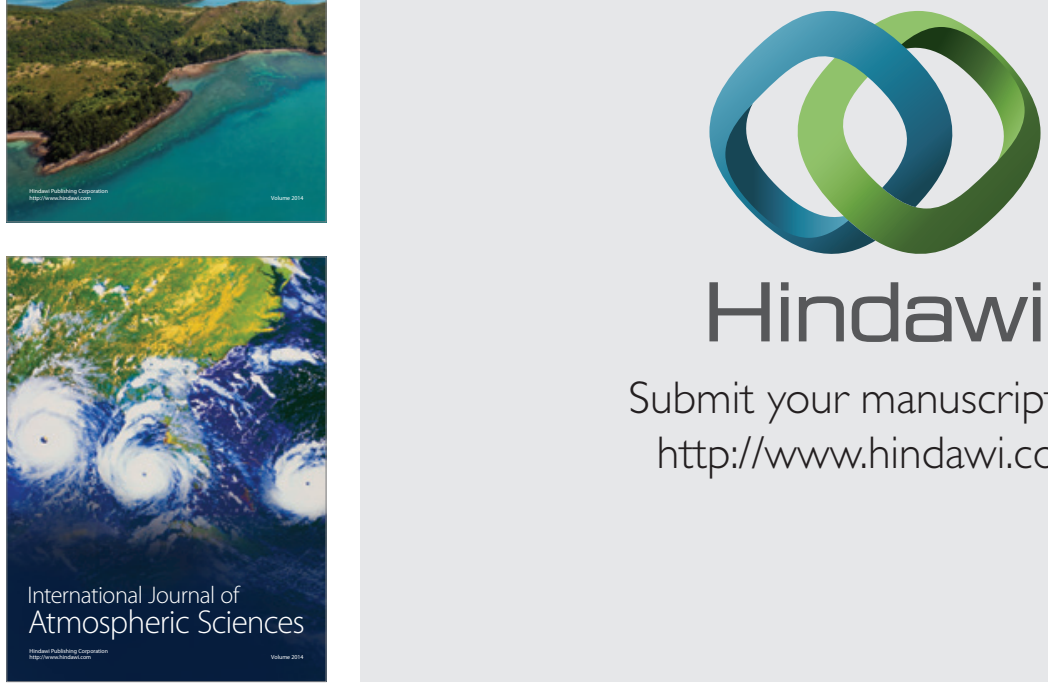

\section{Hindawi}

Submit your manuscripts at

http://www.hindawi.com
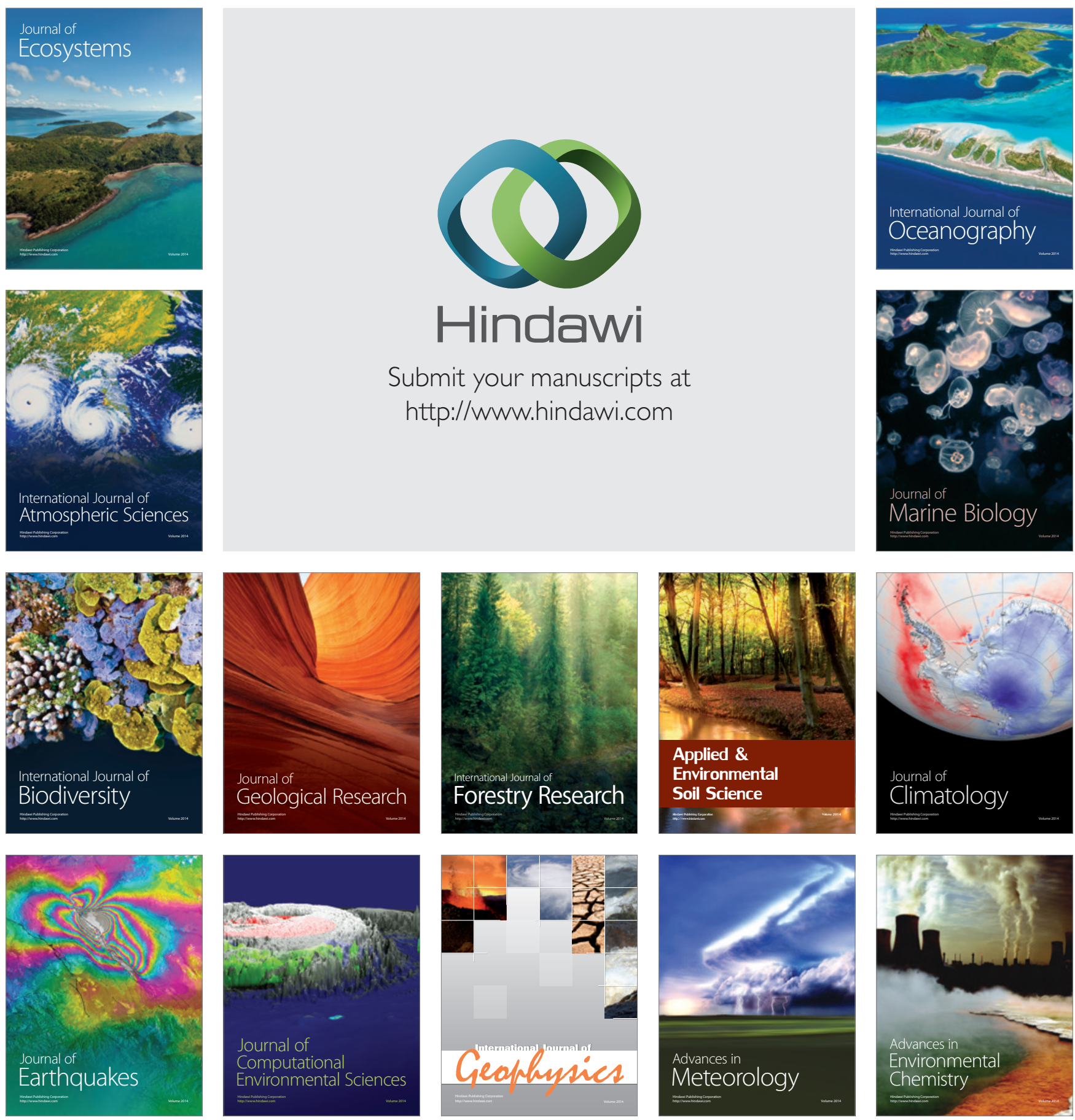